\title{
Optimal Design and Dispatch of Electrically Driven Heat Pumps and Chillers for a New Development Area
}

\author{
Henrik PIEPER ${ }^{1 *}$, Torben OMMEN ${ }^{2}$, Brian ELMEGAARD $^{3}$, Anna VOLKOVA $^{4}$, \\ Wiebke BRIX MARKUSSEN ${ }^{5}$ \\ ${ }^{1,4}$ Tallinn University of Technology, Ehitajate tee 5, 19086 Tallinn, Estonia \\ 2,3, ${ }^{5}$ Technical University of Denmark, Nils Koppels Allé Building 403, 2800 Kgs. Lyngby, Denmark
}

\begin{abstract}
Large-scale heat pumps (HPs) and refrigeration plants are essential technologies to decarbonise the heating and cooling sector. District heating and cooling (DHC) can be supplied with low carbon footprint, if power generated from renewable energy sources is used. The simultaneous supply of DHC is often not considered in energy planning, nor the characteristics of the heat source and sink. Simplified approaches may not reveal the true potential of HPs and chillers. In this paper, different heat sources and sinks and their characteristics were considered for the simultaneous supply of DHC based on large-scale HPs and refrigeration plants. An optimization model was developed based on mixed-integer linear programming. The model is able to identify ideal production and storage capacities, heat sources and sinks based on realistic hourly operation profiles. By doing so, it is possible to identify the most economical or sustainable supply of DHC using electricity. The optimization model was applied to the Nordhavn area, a new development district of Copenhagen, Denmark. The results show that a combination of different heat sources and sinks is ideal for the case study. A HP that uses the district cooling network as a heat source to supply DHC was shown to be very efficient and economical. Groundwater and sewage water HPs were proposed for an economical supply of district heating. The Pareto frontier showed that a large reduction in annual $\mathrm{CO}_{2}$ emissions is possible for a relatively small increase in investments.
\end{abstract}

Keywords - District cooling; district heating; energy planning; heat source; heat sink; large-scale heat pump; mixed-integer linear programming; optimization

\section{INTRODUCTION}

Many studies have shown that district heating (DH) is an essential technology to reach the EU's goal of decarbonizing the energy supply. This may be achieved by expanding the share of the DH heat supply, improving current DH networks, converting DH to the $4^{\text {th }}$ generation of DH and/or by exploiting synergies between thermal networks and electrical grids [1]-[4]. Methods of evaluating the current state of a $\mathrm{DH}$ network and determining the main improvement potentials are presented in Volkova et al. [5]. One of the synergies to exploit, as identified by Lund et al. [4], is to use power-to-heat options. This would allow using intermittent power generated from renewable energy sources (RES) to produce heat. Similarly, electricity may be used to provide cooling. In 2015, cooling demands in the EU

\footnotetext{
* Corresponding author.

E-mail address: henrik.pieper@taltech.ee 
were estimated to account for only $2 \%$ of the final energy consumption [6]. However, it is expected that they will have a strong growth in the future. In addition, cooling demands are often not measured and available information about them is limited. Different studies have investigated district cooling (DC) systems and how they can be optimized, e.g. from an exergoeconomic perspective by Čož et al. [7].

Realised heat pump (HP) projects in Denmark [8] and Europe [9] differ among others in size, heat source, supply temperature and performance. These parameters have an impact on the investments, which makes it difficult to estimate expected costs and to plan new HP projects. Various heat sources and heat $\operatorname{sinks}^{\dagger}$ exist that may be suitable for HPs to supply $\mathrm{DH}$ and/or for refrigeration plants to supply DC at the required temperatures. Each heat source/sink has its own characteristics. They may have varying temperature levels and be limited in capacity or availability. A few studies have investigated different heat sources and sinks. Berntsson [10] analyzed the most common heat sources for HPs used in Sweden. Lund and Persson [11] identified the most suitable heat sources for HPs, which could be introduced in DH networks in Denmark. Gaudard et al [12] investigated the potential of using lakes and rivers in Switzerland as heat source and heat sinks for heating and cooling purposes. The choice of heat source or sink and their temperature variations may have a strong influence on the HP and chiller coefficient of performance (COP), as shown by Pieper et al. [13]. The COP will vary during the year depending on the variations of heat source/sink and network temperatures, as shown e.g. for residential air-to-water HPs in Latvian climate [14].

Several studies have investigated the potential of integrating HPs in energy systems for an efficient integration of large amounts of RES. HPs and chillers are often represented in a simplified way in energy planning tools by e.g. assuming a constant COP, as in [15]-[18], or by basic estimations, such as assuming a constant Lorenz efficiency, which is then multiplied by the Lorenz COP to represent a real cycle [19], [20]. Planning tools for DC often consider the cooling sector in a high level of detail, but may not consider the supply of DH. Examples of such planning tools are the INDIGO Planning tool - IndPT [21], Pack Calculation Pro [22] or the RESCUE Impact calculator [23]. If they do, the coupling of DH and DC may be simplified or the optimization is limited, as in Fjernkøling 2.0 [24].

The objective of the current research is to develop an optimization tool that is able to identify the most economical or environmental attractive electrically driven supply of both DH and DC. These include large-scale HPs, electric boilers, chillers and heat exchangers for direct free cooling (free coolers), supported by hot and cold storage. Different characteristics of the heat sources and sinks were considered by estimating the COP according to actual source and sink stream temperatures, by investments associated to the heat source type and by potential savings by planning the supply of DH and DC simultaneously.

\section{Methods}

An overview of the system layout is shown in Fig. 1. The model is able to identify ideal DH and DC supply based on a combination of three options. Option I represents a supply of DH and DC independently from each other. DH would be supplied by large-scale HPs and hot water storage. DC would be supplied by chillers, free coolers and cold water storage. Option II considers in addition the simultaneous supply of DH and DC by a HP, which uses the return water of the DC network as the heat source to supply DH. The cooled water is used to supply

\footnotetext{
$\dagger$ Heat sink: Heat is released to the media. Heat source can be the same media (e.g. water, air) with different purpose (heat removal instead of receiving heat).
} 
DC. The term district cooling heat pump (DC HP) is here used. One of the conditions for this plant is that the supply of heat from the DC HP to the DH network is directly dependent on the supply of cooling from the DC HP to the DC network. Hot and cold storages may be used to decouple the production of heat and cooling from the cooling and heat demand. In option III, investments for common installations may be shared, i.e. a HP and a chiller could use the same source/sink. Thereby, the same equipment may be used to access the heat source/sink, which could save investments for pre-investigations and installations regarding the access. This setup could be beneficial for sources/sinks that are further away and expensive to establish. The same heat source/sink may be used during different times of the year.

The developed model was applied to the Nordhavn area in Copenhagen, Denmark. DH supplies $98 \%$ of the heat demand in the city [25]. In 2014, the three major utility companies reported that $300 \mathrm{MW}$ of large-scale HPs may be required by 2035 to supply sustainable and cheap DH without depending on biomass only [26]. Nordhavn may be a good showcase for implementing large-scale HPs for supplying a high degree of $\mathrm{CO}_{2}$ neutral heat. It is a residential and commercial development region, located by the sea and will be gradually expanded to accommodate 40000 inhabitants and 40000 jobs until 2060 [27]. For this study, Nordhavn at a future development stage was considered. An hourly peak heat demand of $40 \mathrm{MW}$ and a cooling demand of $10 \mathrm{MW}$ are expected.

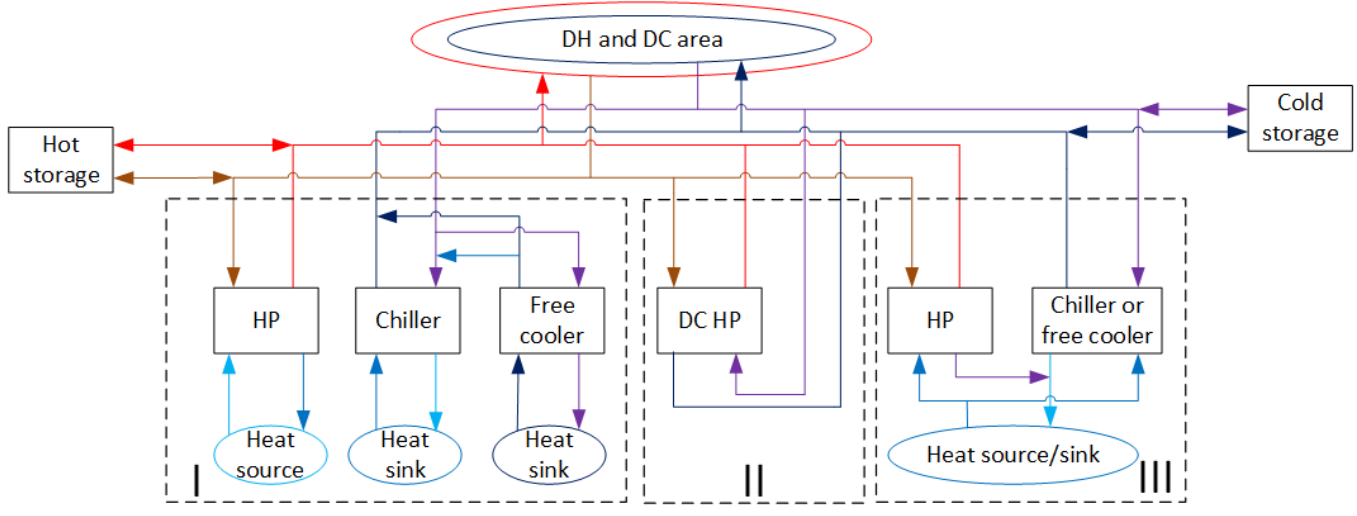

Fig. 1. System layout of supplying DH and DC in different ways.

\subsection{Optimization Model}

The optimization model was developed in the General Algebraic Modelling System (GAMS, version 24.8.3) [28] to investigate which heat sources, heat sinks and/or combination of them are best suited for HPs and chillers to supply DH and DC. The model is able to identify optimal capacities of production plants and storages as well as their hourly operation. Mixedinteger linear programming was used to minimize total annualized costs, as shown in Eq. (1). These costs include annualized investments of the DH network, the DC network, hot storage and cold storage. Other costs are associated to each heat source/sink $p$, which are the annualized investments for HPs, chillers and free coolers, electricity costs, O\&M costs, and the annualized investments for additional piping that may be required between the location of the heat source/sink and the plants. 


$$
\begin{aligned}
& \min Z=C_{D H, a}+C_{s t, a}+\sum_{p}\left(C_{e l, a, p}+C_{m, a, p}+C_{H P, a, p}+C_{p i p e, a, p}\right)+ \\
& +C_{D C, a}+C_{s t, a, c}+\sum_{p}\left(C_{e l, a, p, c}+C_{m, a, p, c}+C_{H P, a, p}+C_{p i p e, a, p, c}+C_{f r e e, a, p}\right)
\end{aligned},
$$

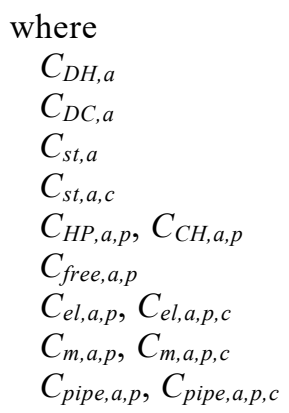
Annualized investments of the DH network; Annualized investments of the DC network; Annualized investments of hot storage; Annualized investments of cold storage; Annualized investments for HPs, chillers; Annualized investments for free coolers; Electricity costs, O\&M costs;

Investments were annualized to reduce calculation time as shown in Eq. (2), considering the lifetime of the technology, $T$, and discount rate, $r$.

$$
C_{I n v, a}=C_{I n v} \frac{r}{(1+r)\left(1-(1+r)^{-T}\right)}
$$

Investments of large-scale HPs, distinguished by the heat source, were obtained from previous research [29], [30]. Investments for chillers and free coolers were taken from [24]. These costs were not differentiated by the heat sink, except for the use of groundwater. The piping costs to access the heat sources/sinks from the expected plant location were based on [31]. They consisted of a constant parameter per meter pipe length and one term depending on the pipe diameter, consequently also on the capacity.

If the DH and DC production units would be established simultaneously, parts of the investments could be shared equally between the heating and the cooling side. This may result in lower investments than supplying DH and DC separately. Such costs could be related to piping costs between the heat sources and production units, permissions, drillings and preinvestigations. In addition, investments related to the connection to the electrical grid could be saved. How the investments were considered for HPs as well as for piping between the HP and the heat source are shown in Eq. (3) and Eq. (4). The same applies for chillers for DC.

$$
\begin{gathered}
C_{H P, p}=C_{\min , p} u_{p}+C_{\text {avoid }, p} u_{x, p}+c_{v, p} Q_{d, p} \\
C_{\text {pipe }}=C_{\text {pipe }, l} L_{\text {pipe }} u_{p}+c_{v, \text { pipe }} Q_{d, p}
\end{gathered}
$$

$C_{\text {min, } p}$ contains unavoidable costs for the HP (e.g. for the production units), and $C_{\text {avoid, } p}$ includes costs that could be saved when co-production for DH and DC is installed. $c_{v, p}$ contains variable costs depending on the installed capacity. $c_{p i p e, l}$ contains costs depending on the pipe length, $L_{\text {pipe }}$, and $c_{v, \text { pipe }}$ costs considering the capacity.

To ensure that piping costs to access a heat sink are not paid twice for the case of using chillers and free coolers for the same heat sink, the investments of implementing free cooling were calculated as shown in Eq. (5). The first term represents a required minimum cost for establishing such system. The second term represents a fixed cost for the free cooler depending on the installed capacity. The third term represents the piping costs that may be 
required between the heat sink and the plant. The variable $u_{x, \text { free }}$ will be zero, if both free coolers and chillers are installed to ensure not to pay piping costs twice. Otherwise, it is one.

$$
C_{\text {free }}=C_{\text {min, free }} u_{\text {free }}+c_{v, \text { free }} Q_{d, \text { free }}+u_{x, \text { free }} C_{\text {free, pipe }}
$$

Annual O\&M costs for HPs were taken from [8] and consisted of parameters depending on the installed HP capacity and on the amount of supplied heat. The O\&M costs for chillers and free coolers were assumed to be $2 \%$ of the total investments of the cooling plant and $3 \%$ if groundwater was used [24]. The annual costs for electricity consumption of the HPs, chillers and free coolers were based on the day-ahead hourly electricity price in 2018, taxes of $20 € / \mathrm{MWh}_{\mathrm{el}}$ [32] and different tariffs summing up in 23.85 $€ / \mathrm{MWh}_{\mathrm{el}}$ [33], [34].

\subsubsection{District Heating Supply}

The hourly heat demand had to be supplied by the production units or the storage, as shown in Eq. (6). The sum of generated heat of each production unit $Q_{H P, p, n}$ was for every hour $n$ in balance with the heat demand $Q_{D H, n}$ the pipe heat loss $Q_{p i p e, l o s s, n}$ and the difference of stored and used heat from the storage $\left(Q_{s t, c h a r, n}-Q_{s t, d i s, n}\right)$. Additional details of modelling the supply of DH can be found in Pieper et al. [35].

$$
\sum_{p} Q_{H P, p, n}=Q_{D H, n}+Q_{\text {pipe }, \text { loss }, n}+Q_{\text {st.char }, n}-Q_{\text {st.dis }, n}
$$

The model determined the required HP design capacity of each heat source $Q_{H P, d, p}$ and storage capacity by Eq. (7)-(9), ensuring that the capacities were above the hourly production and storage level, respectively. The minimum HP capacity $Q_{H P, \min , p}$ and the binary variable $u_{\text {min,p,n }}$ were introduced to require a minimum HP load of 1 MW during operation. This corresponds to a minimum part-load of $25 \%$ for a 4 MW HP. If the capacity would be larger, the HP will likely consist of several smaller units of e.g. 4 MW. Part-load operation of HPs was not included in the model.

$$
\begin{gathered}
Q_{H P, d, p} \geq Q_{H P, p, n} \\
Q_{H P, p, n} \geq Q_{H P, \min , p} u_{\min , p, n} \\
Q_{s t, c} \geq Q_{s t, \text { level }, n}
\end{gathered}
$$

The storage level of hour $n$ was determined by Eq. (10), which includes the storage level of the previous hour $Q_{s t, l e v e l, n-1}$, the amount of heat the storage is charged and discharged with and the storage heat loss factor $f_{\text {loss }}$.

$$
Q_{s t, l e v e l, n}=Q_{s t, l e v e l, n-1}+Q_{s t, \text { char }, n}-Q_{s t, \text { is }, n}-f_{\text {loss }} Q_{\text {st }, \text { level }, n}
$$

The hourly electricity consumption $P_{p, n}$ of each production unit $p$ was determined by the ratio of hourly-generated heat and the hourly HP COP for heating (COP) of each production unit, as shown in Eq. (11). An electric boiler was assumed to be used as peak load unit with constant COP of 1, which may be seen as an additional production unit such as a HP.

$$
P_{p, n}=\frac{Q_{H P, p, n}}{C O P_{p, n}}
$$


If the DC network is used as a heat source for HPs to supply DH, both commodities could be supplied simultaneously using one production unit. This required that the production of heat $Q_{H P, D C, n}$ and cooling $Q_{C H, D C, n}$ of the DC HP was linked by the following equation:

$$
Q_{H P, D C, n}=Q_{C H, D C, n} \frac{C O P_{D C}}{C O P_{D C}-1}
$$

\subsubsection{District Cooling Supply}

The supply of DC for every hour $n$ was modelled according to Eq. (13), considering the production of free cooling $Q_{\text {free, }, n}$ and mechanical cooling $Q_{C H, p, n}$ of each heat sink $p$, the DC demand $Q_{D C, n}$, storage charging $Q_{s t . c h a r, c, n}$ and discharging $Q_{s t . d i s, c, n}$.

$$
\sum_{p}\left(Q_{C H, p, n}+Q_{\text {free }, p, n}\right)=Q_{D C, n}+Q_{s t . c h a r, c, n}-Q_{s t . d i s, c, n}
$$

The conditions for heating from Eq. (7) to Eq. (10) were also applied for cooling considering chillers, free coolers and cold storage. However, no minimum cooling capacity for a production unit was set. Free cooling was included as a direct heat exchange between the heat sink and the DC network. The amount of free cooling $Q_{\text {free, } n}$ that could be generated from each heat sink $n$ was limited over the year depending on the temperature levels. $100 \%$ free cooling may be achieved for heat sink inlet temperatures $T_{\sin k, i, n}$ lower than the DC supply temperature $\left(T_{D C, s}\right)$ minus a pinch point temperature difference of $\Delta T_{\text {free }}=3 \mathrm{~K}$ (Eq. (14)). Free cooling was not possible for heat sink inlet temperatures higher than the DC return temperature $\left(T_{C D, r}\right)$ minus the pinch point temperature difference (Eq. (15)). A mix of mechanical and free cooling was possible for heat sink temperatures between the DC supply and return temperature (Eq. (16)).

$$
\begin{gathered}
Q_{\text {free }, n}=m_{\text {free }, n} c_{p, \text { sink }, n}\left(T_{D C, r}-T_{D C, s}\right) \forall T_{\text {sink }, i, n} \leq T_{D C, s}-\Delta T_{\text {free }} \\
Q_{\text {free }, n}=0 \forall T_{\text {sink }, i, n} \leq T_{D C, s}-\Delta T_{\text {free }} \\
Q_{\text {free }, n}=m_{\text {free }, n} c_{p, \text { sink }, n}\left(T_{D C, r}-\Delta T_{\text {free }}-T_{\text {sink }, i, n}\right) \\
\forall T_{D C, s}-\Delta T_{\text {free }}<T_{\text {sink }, i, n}<T_{D C, r}-\Delta T_{\text {free }}
\end{gathered}
$$

Eq. (17) and Eq. (18) were used to ensure that free cooling was not used more than technically feasible, i.e. free energy transfer from a cold to a warm reservoir by using storage.

$$
\begin{gathered}
Q_{\text {free }, n} \leq V_{D C, n} \rho_{D C} c_{p, D C}\left(T_{D C, r}-T_{\text {free }, n}\right) \\
\forall T_{D C, s}-\Delta T_{\text {free }}<T_{\text {sink }, i, n}<T_{D C, r}-\Delta T_{\text {free }} \\
T_{\text {free }, n}=T_{\text {sink }, i, n}+\Delta T_{\text {free }}
\end{gathered}
$$

The hourly electricity consumption of cooling equipment was determined by Eq. (19). Fan power (air) or pumping for the free coolers was considered by assuming $f_{\text {free }}$ to $2 \%$ and a linear relationship to capacity. The cooling COP $\left(C O P_{c}\right)$ was used instead of the heating COP.

$$
P_{c, p, n}=P_{C H, p, n}+P_{f r e e, p, n}=\frac{Q_{C H, p, n}}{C O P_{c, p, n}}+f_{\text {free }} Q_{\text {free }, p, n}
$$




\subsubsection{Pareto Frontier for Minimizing Annual $\mathrm{CO}_{2}$ Emissions}

The objective function was to minimize total costs. Alternatively, annual $\mathrm{CO}_{2}$ emissions from electricity consumption of the production plants could be minimized. Consequently, it is possible to obtain the most sustainable solution by including hourly $\mathrm{CO}_{2}$ emissions [36] and the electricity consumption of HPs, chillers and free coolers, as in Eq. (20).

$$
\min Z_{C O 2}=\sum_{n} \sum_{p} C O_{2, n}\left(P_{H P, p, n}+P_{C H, p, n}+P_{\text {free }, p, n}\right)
$$

In case both total costs and $\mathrm{CO}_{2}$ emissions should be minimized, this assessment changes into a multi-objective optimization problem. A Pareto frontier was created showing the dependencies in terms of lowest $\mathrm{CO}_{2}$ emissions and total annual costs. The preference-based method described in Soroudi [37] was used. The multi-objective optimization problem was converted into a single-objective optimization problem. This was then solved several times in a loop by adjusting the upper or lower bound of the second objective.

\subsection{Approximation of COP-Values Based on Actual Temperatures}

The HP COP and chiller COPc were estimated based on thermodynamic models according to the design temperatures of the DH and DC networks, the heat sources and sinks, following the method from Pieper et al. [13]. Linear regression was used in order to estimate a realistic $C O P$ for other operating temperatures of heat source/sink and the networks than the design, as shown in Eq. (21). More information can be found in Pieper [30]. A requirement for this method is the availability of a thermodynamic model for design and off-design conditions. An alternative generalized method is proposed in Ommen et al. [38]. The parameters used for $C O P$ and $C O P c$ for design and off-design operation are stated in Table 1 and Table 2, respectively. $T_{\text {source, } i}$ stands for the heat source or sink inlet temperature, $T_{D H, s ; D C, r}$ for the DH supply temperature or DC return temperature and the subscript $d$ for design conditions. The parameter c represents an off-set of the design $C O P$ for the temperature ranges not including the design temperatures, e.g. air, groundwater and seawater.

TABLE 1. COEFFICIENTS FOR COP ESTIMATION

\begin{tabular}{llllllll}
\hline Parameter & $\begin{array}{l}\text { Air }\left(-\mathbf{1 2}^{\circ} \mathbf{C} \leq\right. \\
\left.\boldsymbol{T}_{\text {air }} \leq \mathbf{1 8}{ }^{\circ} \mathbf{C}\right)\end{array}$ & $\begin{array}{l}\text { Air }\left(\mathbf{1 8}^{\circ} \mathbf{C}<\boldsymbol{T}_{\text {air }}\right. \\
\left.\leq \mathbf{3 2}^{\circ} \mathbf{C}\right)\end{array}$ & $\begin{array}{l}\mathbf{G W}\left(\mathbf{0}^{\circ} \mathbf{C} \leq\right. \\
\left.\boldsymbol{T}_{\mathbf{G W}}<\mathbf{1 0}{ }^{\circ} \mathbf{C}\right)\end{array}$ & $\begin{array}{l}\mathbf{G W}\left(\mathbf{1 0}{ }^{\circ} \mathbf{C} \leq\right. \\
\left.\boldsymbol{T}_{\mathbf{G W}} \leq \mathbf{2 5}{ }^{\circ} \mathbf{C}\right)\end{array}$ & Sew & Sea & DC \\
\hline$T_{\text {source }, i, d}$ & -12 & -12 & 10 & 10 & 11 & 3 & 16 \\
$C O P_{d}$ & 2.88 & 2.88 & 3.85 & 3.85 & 3.91 & 3.68 & 3.96 \\
$a$ & 0.0408 & 0.0650 & 0.0238 & 0.0553 & 0.0562 & 0.0529 & 0.0148 \\
$b$ & 0.0122 & 0.0122 & 0.0283 & 0.0283 & 0.0290 & 0.0262 & 0.0274 \\
$c$ & 0 & -0.7529 & 0.0361 & 0 & 0 & 0 & 0 \\
\hline
\end{tabular}

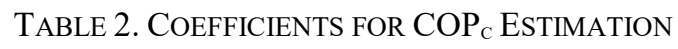

\begin{tabular}{|c|c|c|c|c|c|c|}
\hline Parameter & $\operatorname{Air}\left(5^{\circ} \mathrm{C} \leq T_{\text {air }}<17^{\circ} \mathrm{C}\right)$ & $\begin{array}{l}\operatorname{Air}\left(17^{\circ} \mathrm{C} \leq\right. \\
\left.\mathrm{T}_{\text {air }} \leq 35^{\circ} \mathrm{C}\right)\end{array}$ & GW & Sew & $\begin{array}{l}\text { Sea }\left(1^{\circ} \mathrm{C} \leq\right. \\
\left.\mathrm{T}_{\text {sea }}<9^{\circ} \mathrm{C}\right)\end{array}$ & $\begin{array}{l}\text { Sea }\left(9^{\circ} \mathrm{C} \leq\right. \\
\left.\mathrm{T}_{\text {sea }} \leq 22^{\circ} \mathrm{C}\right)\end{array}$ \\
\hline $\bar{T} T_{\text {source }, i, d}$ & 35 & 35 & 10 & 25 & 22 & 22 \\
\hline$C O P_{c, d}$ & 4.24 & 4.24 & 10.4 & 5.68 & 6.28 & 6.28 \\
\hline$a$ & -0.5819 & -0.1752 & -0.5062 & -0.2631 & -0.6388 & -0.3191 \\
\hline$b$ & -0.0557 & -0.0557 & -0.1830 & -0.0732 & -0.0897 & -0.0897 \\
\hline$c$ & -7.566 & 0 & 0 & 0 & -4.096 & 0 \\
\hline
\end{tabular}




\subsection{Performance Indicators}

Different indicators were calculated to evaluate the system based on technical, economic and environmental parameters. The indicators are stated for the use of HPs, but were also applied to the case of cooling considering the required adjustments, e.g. evaporator capacity as cooling supply capacity instead of condenser capacity as heating supply capacity. A seasonal $C O P$ of HPs $\left(S C O P_{H P}\right)$ was calculated, which considers the operating hours of HPs:

$$
\operatorname{SCOP}_{H P, p}=\frac{\sum_{n=1}^{N} Q_{H P, p, n}}{\sum_{n=1}^{N} P_{p, n}}
$$

The $S C O P_{H P, p}$ was calculated as the ratio of total generated heat and total consumed electrical energy over the entire year of each HP using another heat source. A system $S C O P_{D H C}$ was defined as the total supplied heat and cooling divided by the total consumed electrical energy from all units, as shown in Eq. (23).

$$
S C O P_{D H C}=\frac{Q_{D H}+Q_{D C}}{P_{H P, t o t}+P_{C H, t o t}+P_{\text {free }, \text { tot }}}
$$

The levelized costs of heat $(\mathrm{LCOH})$ included all costs of producing the heat divided by the annual production of heat $Q_{a, p}$, as shown in Eq. (24). Similarly, the levelized costs of cooling $(L C O C)$ were determined considering also the free coolers.

$$
L C O H_{H P, p}=\frac{C_{e l, a, p}+C_{m, a, p}+C_{H P, a, p}+C_{D H, a, p}}{Q_{a, p}}
$$

$\mathrm{CO}_{2}$ emissions based on consumed electricity were calculated by considering the hourly electricity consumption multiplied by the hourly $\mathrm{CO}_{2}$ emission and divided by the heat/cooling production [36]. For the DC HP, the $\mathrm{CO}_{2}$ emissions were divided equally.

\subsection{Input Parameters}

The utility company HOFOR conducted hourly measurements in 2018 of the heat demand of the already existing building area of Nordhavn [39]. The measurements were scaled up in order to meet the hourly peak heat demand expected at the future development stage. The annual heat demand added up to $100 \mathrm{GWh}$. For cooling, hourly values were taken from the software tool Fjernkøl 2.0 [24] using profile 7. The cooling demand profile was scaled up to meet the hourly peak demand. This included adding a constant base load of $1 \mathrm{MWh} / \mathrm{h}$, which resulted in an annual share of $55 \%$ base load. This is consistent with the findings of Tvärne et al. [40]. An overview of the heat and cooling demands can be found in Fig. 2. The supply and return temperatures of the $\mathrm{DH}$ network were set to be $65^{\circ} \mathrm{C}$ and $40{ }^{\circ} \mathrm{C}$, respectively. The DC supply and return temperatures were set at $6^{\circ} \mathrm{C}$ and $16^{\circ} \mathrm{C}$, respectively. 


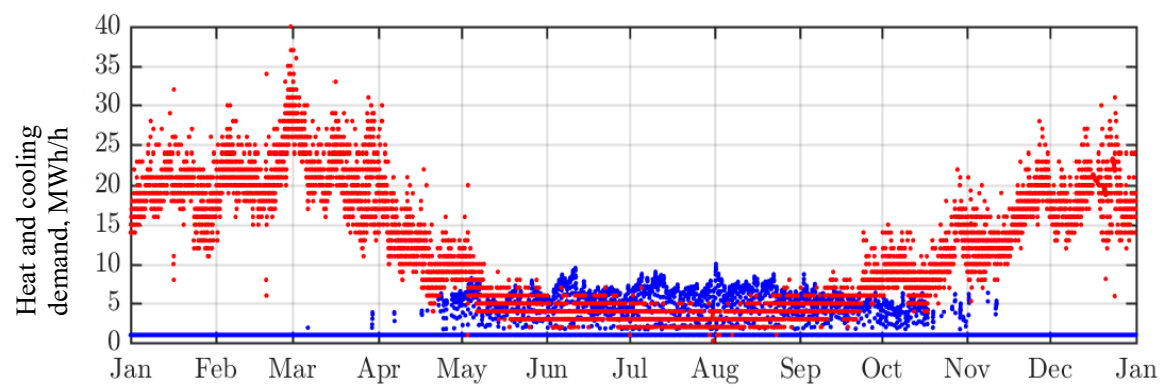

Fig. 2. Heat and cooling demand for Nordhavn.

Ambient air, groundwater, seawater, sewage water and the DC network were identified as potential heat source and when possible as a heat sink. The inlet temperatures were determined as described in Pieper et al. [13] and are shown in Fig. 3.

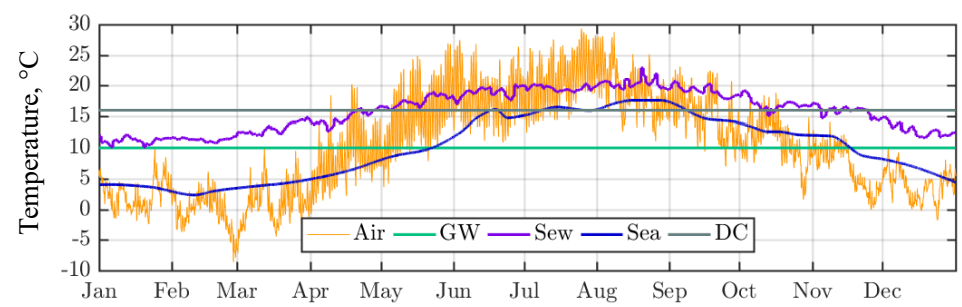

Fig. 3. Heat source temperatures of air (Air), groundwater (GW), sewage water (Sew), seawater (Sea) and DC (DC).

\section{RESults}

The total annual costs for the optimized system and its operation were 4.03 million EUR. The $S C O P_{D H C}$ of the system was 4.30 . The total $\mathrm{CO}_{2}$ emissions of the system would be $6054 \mathrm{t}$. An overview of other parameters is shown in Table 3 and Table 4 . The ideal production capacities would be a 5.00 MW groundwater HP, a 15.44 MW sewage water HP, a 6.05 MW electric boiler, a 4.05 MW DC HP (corresponding to $3.03 \mathrm{MW} \mathrm{DC}$ supply) and a $0.69 \mathrm{MW}$ air chiller. This is a combination of option I and II from Fig. 1. Saving investments based on option III or make use of free cooling was not chosen for the specific case study. The DC HP was used to cover most of the cooling demand, while supplying DH simultaneously. In summer, air chillers supply the remaining DC demand, which was not supplied by the DC HP. This shows that the use of a DC HP is very economical. The storage capacities of $257 \mathrm{MWh}$ hot and $49 \mathrm{MWh}$ cold water allow to keep the production capacities small, i.e. $76 \%$ of the peak heat demand and $37 \%$ of the peak cooling demand, respectively. The $\mathrm{CO}_{2}$ emissions differ for each heat source according to the HP and chiller COPS and the hourly $\mathrm{CO}_{2}$ emissions. The $L C O H$ were $35.55 € / \mathrm{MWh}_{\mathrm{h}}$ and the $L C O C$ were $28.61 € / \mathrm{MWh}_{\mathrm{c}}$. The different contributions to the $L C O H$ and $L C O C$ can be found in Fig. 4. 
TABLE 3. DH SUPPLY FOR NORDHAVN

\begin{tabular}{lllllll}
\hline Parameter & GW & Sew & DC & El. Boiler & Total & Unit \\
\hline Heat pump capacity & 5.00 & 15.44 & 4.05 & 6.05 & 30.54 & $\mathrm{MW}$ \\
Hot storage capacity & & & & & 257 & $\mathrm{MWh}$ \\
Seasonal $\mathrm{COP}$ & 3.87 & 4.07 & $3.96^{*}$ & 1.00 & $3.87^{*}$ & - \\
Levelized costs of heat & 35.81 & 36.02 & 19.94 & 148.71 & 35.55 & $€ / \mathrm{MWh}_{\mathrm{h}}$ \\
$\mathrm{CO}_{2}$ emissions & 61.42 & 56.78 & 22.95 & 244.05 & 55.43 & $\mathrm{kgCO}_{2} / \mathrm{MWh}_{\mathrm{h}}$ \\
\hline
\end{tabular}

*The benefit of supplying heating and cooling simultaneously was not considered.

TABLE 4. DC SUPPLY FOR NORDHAVN

\begin{tabular}{lllll}
\hline Parameter & Air & DC & Total & Unit \\
\hline Chiller capacity & 0.69 & 3.03 & 3.72 & $\mathrm{MW}$ \\
Cold storage capacity & & & 49 & $\mathrm{MWh}$ \\
Seasonal COP & 7.13 & $2.96^{*}$ & $3.09^{*}$ & - \\
Levelized costs of cooling & 62.50 & 25.44 & 28.61 & $€ / \mathrm{MWh}_{\mathrm{c}}$ \\
$\mathrm{CO}_{2}$ emissions & 27.18 & 30.70 & 30.45 & $\mathrm{kgCO}_{2} / \mathrm{MWh}_{\mathrm{c}}$ \\
\hline
\end{tabular}

*The benefit of supplying heating and cooling simultaneously was not considered.

As shown in Fig. 4, costs related to electricity consumption, including taxes and fees, contribute with more than $50 \%$ to the overall costs. The costs for investments into HPs, boiler and chillers correspond to approximately $25 \%$ of the total costs. The remaining part is related to investments for the $\mathrm{DH}$ network expansion, storage and piping between the heat source/sink access and the plant.

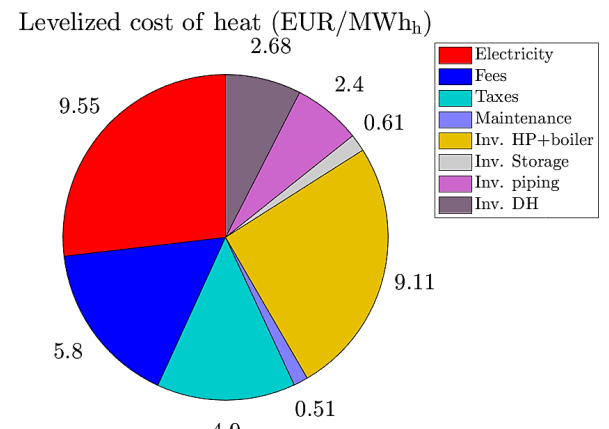

4.9

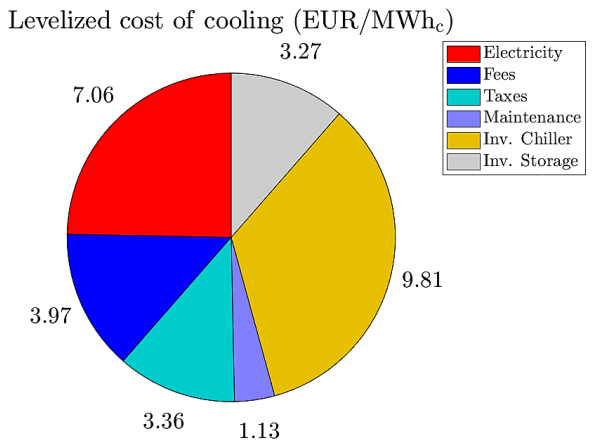

1.13

Fig. 4. $\mathrm{LCOH}$ and $L C O C$ for the most economical supply of DH and DC.

The hourly operation of the production plants and storage (difference between production and demand) to supply DH and DC is illustrated exemplary for February and June in Fig. 5. It shows that the operation is driven by the electricity price to reduce costs. Thereby, the production plants are used to their full capacity during low prices to charge the storages, which are then used during high prices. 


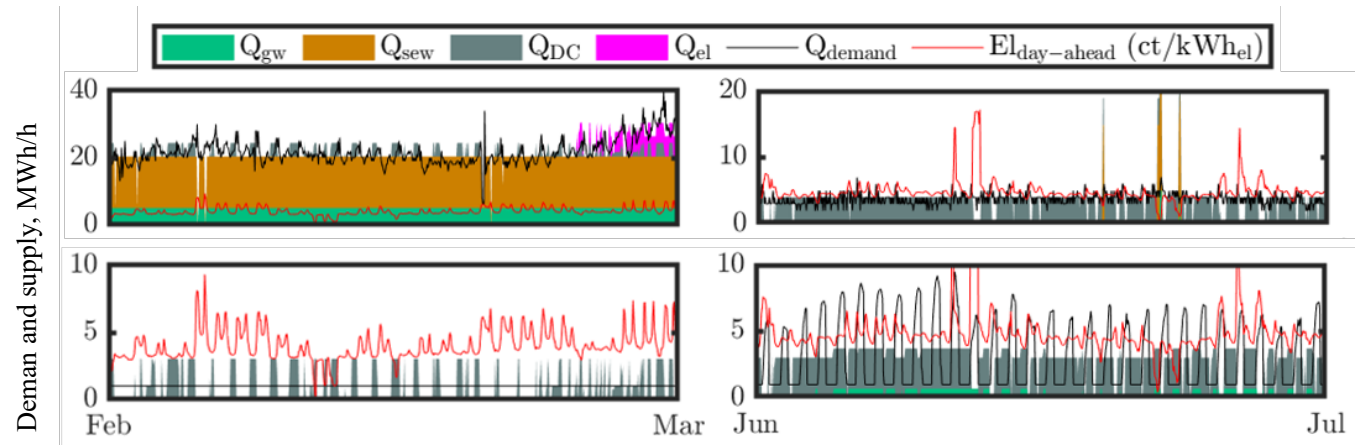

Fig. 5. Hourly supply of DH (above) and DC (below) and electricity day-ahead prices for January and February.

As shown in Fig. 6, the Pareto frontier identified solutions compromising minimum total annual costs and $\mathrm{CO}_{2}$ emissions based on electricity consumption. If fewer $\mathrm{CO}_{2}$ emissions should be emitted, the total annual costs would increase accordingly, because the chosen capacities were larger in order to operate according to the hourly $\mathrm{CO}_{2}$ emissions from electricity production. By increasing the annual costs to e.g. 5.25 million EUR, the annual $\mathrm{CO}_{2}$ emissions would decrease to $4123 \mathrm{t}$ (green dot). However, increasing the total annual costs by only $40000 €$ would lead to a reduction of $483 \mathrm{t} \mathrm{CO}_{2}$ emissions annually (orange dot).

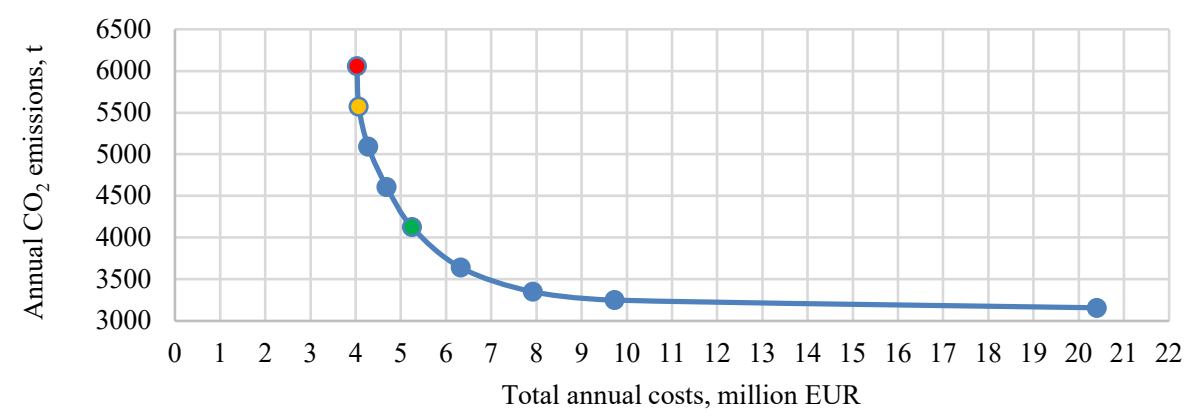

Fig. 6. Pareto frontier of annual $\mathrm{CO}_{2}$ emissions and total annual costs.

\section{Discussion}

The COP estimation was based on a thermodynamic model to improve its accuracy compared to other estimations used. The used parameters for off-design operation depend on the design conditions. Other parameters might apply for different conditions. Approximating these would require the use of the thermodynamic model. Part-load behaviour of HPs and chillers was not included in the optimization. However, Pieper [30] showed for a thermodynamic model that the HP COP did not vary considerably for part-loads above $25 \%$. Alternatively, the COP estimation method based on Ommen et al. may be used [38]. An analysis of the impact of using different HP COP estimations in energy planning is given in Pieper et al. [13]. The DH and DC network itself has not been modelled. It was assumed that this may not affect the potential solutions, since the total installed capacities would be similar. 
A stratified storage was not modelled. Therefore, hydraulics were not considered, which could impact charging or discharging of the storage and the temperature regime. Nordhavn was used as a case study to show the purpose of the model. The optimal supply of DH and DC for another region could be based on different heat sources and sinks.

\section{CONCLUSION}

A model has been developed to identify ideal capacities and dispatch of both DH and DC production units for a new development area. The study considers five potential heat sources and sinks and their characteristics in detail. It was found that a $5.00 \mathrm{MW}$ groundwater HP, a 15.44 MW sewage water HP, a 6.05 MW electric boiler, a 4.05 MW DC HP (3.03 MW DC supply) and a $0.69 \mathrm{MW}$ air chiller would annually supply $51 \mathrm{GWh} \mathrm{DH}$ and $16 \mathrm{GWh}$ DC most economically. This resulted in total annual costs of 4.03 Mio. $€$ and annual $\mathrm{CO}_{2}$ emissions of $6054 \mathrm{t}$. It was shown that the use of a DC HP is a very economical and efficient way to supply DH and DC simultaneously. The Pareto frontier identified how much additional cost would be needed to abate significant carbon-emissions from heat and cooling demands.

\section{ACKNOWLEDGEMENTS}

This research project was funded by the Mobilitas Pluss Postdoctoral Researcher Grant. Project title: "Optimal dimensioning and annual operation of district cooling systems in cold climates with existing district heating". Project number: MOBJD472. Carrying out the analysis for this paper was conducted during a research project funded by EUDP (Energy Technology Development and Demonstration). Project title: "EnergyLab Nordhavn - New Urban Energy Infrastructures", project number: 64014-0555.

\section{REFERENCES}

[1] Connolly D., et al. Heat Roadmap Europe: Combining district heating with heat savings to decarbonise the EU energy system. Energy Policy 2014:65:475-89. http://doi.org/10.1016/j.enpol.2013.10.035

[2] Lund H., et al. 4th Generation District Heating (4GDH). Integrating smart thermal grids into future sustainable energy systems. Energy 2014:68:1-11. http://doi.org/10.1016/j.energy.2014.02.089

[3] Lund H., et al. The role of district heating in future renewable energy systems. Energy 2010:35(3):1381-1390. http://doi.org/10.1016/j.energy.2009.11.023

[4] Lund H., et al. Renewable energy systems - A smart energy systems approach to the choice and modelling of $100 \%$ renewable solutions. Chem. Eng. Trans. 2014:39:1-6. http://doi.org/10.3303/CET1439001

[5] Volkova A., et al. Methodology for the improvement of large district heating networks. Environ. Clim. Technol. 2012:10:39-45. http://doi.org/10.2478/v10145-012-0009-7

[6] Fleiter T., et al. Heat Roadmap Europe: EU Profile of heating and cooling demand in 2015. Heat roadmap EU, 2017.

[7] Čož T. D., Kitanovski A., Poredoš A. Exergoeconomic optimization of a district cooling network. Energy 2017:135:342351. http://doi.org/10.1016/j.energy.2017.06.126

[8] Danish Energy Agency. Inspirationskatalog for store varmepumpeprojekter i fjernvarmesystemet (Inspiration catalogue for large-scale heat pump projects in district heating). Kobenhavn: DAE, 2017.

[9] David A., et al. Supplementary Materials: Heat Roadmap Europe: Large-Scale Electric Heat Pumps in District Heating Systems. Energies 2017:10(4):578. http://doi.org/10.3390/en10040578

[10] Berntsson T. Heat sources - Technology, economy and environment. Int. J. Refrig. 2002:25(4):428-438. http://doi.org/10.1016/S0140-7007(01)00034-2

[11] Lund R., Persson U. Mapping of potential heat sources for heat pumps for district heating in Denmark. Energy 2015:110:129-138. http://doi.org/10.1016/j.energy.2015.12.127

[12] Gaudard A., Wüest A., Schmid M. Using lakes and rivers for extraction and disposal of heat: Estimate of regional potentials. Renew Energy 2019:134:330-42. http://doi.org/10.1016/j.renene.2018.10.095

[13] Pieper H., et al. Comparison of COP estimation methods for large-scale heat pumps used in energy planning. Energy 2020:205:117994. http://doi.org/10.1016/j.energy.2020.117994 
[14] Kazjonovs J., et al. Performance analysis of air-to-water heat pump in Latvian climate conditions. Environ. Clim. Technol. 2014:14(1):18-22. http://doi.org/10.1515/rtuect-2014-0009

[15] Lund R., Ilic D. D., Trygg L. Socioeconomic potential for introducing large-scale heat pumps in district heating in Denmark. Journal of Clean Prod. 2016:139:219-229. http://doi.org/10.1016/j.jclepro.2016.07.135

[16] Hedegaard K., Balyk O. Energy system investment model incorporating heat pumps with thermal storage in buildings and buffer tanks. Energy 2013:63:356-65. http://doi.org/10.1016/j.energy.2013.09.061

[17] Rinne S., Syri S. Heat pumps versus combined heat and power production as $\mathrm{CO}_{2}$ reduction measures in Finland. Energy 2013:57:308-318. http://doi.org/10.1016/j.energy.2013.05.033

[18] Bazbauers G., Cimdina G. The Role of the Latvian District Heating System in the Development of Sustainable Energy Supply. Environ. Clim. Technol. 2011:7(1):27-31. http://doi.org/10.2478/v10145-011-0024-0

[19] Lund R., et al. Comparison of Low-temperature District Heating Concepts in a Long-Term Energy System Perspective. Int. J. Sustain. Energy Plan Manag. 2017:12:5-18. http://doi.org/10.5278/ijsepm.2017.12.2

[20] Østergaard P. A., Andersen A. N. Booster heat pumps and central heat pumps in district heating. Applied Energy 2016:184:1374-1388. http://doi.org/10.1016/j.apenergy.2016.02.144

[21] Rama M., et al. INDIGO Planning tool - IndPT. Zenodo, 2020. http://doi.org/10.5281/zenodo.1407213

[22] IPU. Pack Calculation Pro. Users guide. Version 4.10. Lyngby: IPU, 2015

[23] Eckstadt E. RESCUE Impact Calculator. 2014. Presented at the RESCUE - REnewable Smart Cooling for Urban Europe, Edinburgh, UK, 2014.

[24] Mikkelsen S. E. Værktøj til økonomisk og miljømæssig analyse af hybridanlæg til fjernkøling og fjernvarme - Fjernkøl 2.0. Slutrapport og brugermanual. (Tool for the economical and environmental analysis of hybrid systems for district cooling and district heating - District cooling 2.0 Final report and user manual). Lyngby: COWI, 2013. (in Danish)

[25] HOFOR. District Heating in Copenhagen: Energy-efficient, Low-carbon, and Cost-effective. Kobenhavn: HOFOR, 2016.

[26] CTR, HOFOR, VEKS. Heat Planning for the Greater Copenhagen area, 2014 [Online]. [Accessed 3.05.2017]. Available: http://www.varmeplanhovedstaden.dk/ (in Danish)

[27] Energylab Nordhavn. EnergyLab Nordhavn: New Urban Energy Infrastructures and Smart Components 2016 [Online]. [Accessed 20.09.2017]. Available: http://www.energylabnordhavn.com/about.html

[28] GAMS Development Corp. GAMS [Online]. [Accessed 6.08.2017]. Available: https://www.gams.com/

[29] Pieper H., et al. Allocation of investment costs for large-scale heat pumps supplying district heating. Energy Procedia 2018:147:358-367. http://doi.org/10.1016/j.egypro.2018.07.104

[30] Pieper H. Optimal Integration of District Heating, District Cooling, Heat Sources and Heat Sinks. Lyngby: Technical University of Denmark, 2019.

[31] Danish Energy Agency. District Heating Assessment Tool (DHAT). Kobenhavn: DEA, 2017.

[32] The Danish Ministry of Climate Energy and Utilities. Energiaftale af 29. juni 2018. Energy agrement of 29 June 2018. https://kefm.dk/aftaler-og-politiske-udspil/energiaftalen

[33] Danish Energy. Elforsyningens nettariffer \& priser (Electricity supply system tariffs and prices). Frederiksberg: Dansk Energi, 2018. (in Danish)

[34] Radius. Tariffs and subscription fee 2019 [Online]. [Accessed 15.03.2019]. Available: https://radiuselnet.dk/Elkunder/Priser-og-vilkaar/Tariffer-og-netabonnement (in Danish)

[35] Pieper H., et al. Modelling framework for integration of large-scale heat pumps in district heating using low-temperature heat sources: A case study of Tallinn, Estonia. Int. J. Sustain. Energy Plan. Manag. 2019:20:67-86. http://doi.org/10.5278/ijsepm.2019.20.6

[36] Energinet. $\mathrm{CO}_{2}$ Emission Data 2018. https://www.energidataservice.dk/tso-electricity/co2emis

[37] Soroudi A. Power System Optimization Modeling in GAMS. Springer International Publishing, 2017. http://doi.org/10.1007/978-3-319-62350-4

[38] Ommen T., et al. Generalized COP estimation of heat pump processes for operation off the design point of equipment. Proc 25th IIR Int Congr Refrig 2019:648. https://doi.org/10.18462/iir.icr.2019.0648

[39] HOFOR. Heat demand data for Nordhavn for 2018 [Online]. [Accessed 17.02.2019]. Available: https://energydata.dk/

[40] Tvärne A., et al. EU District Cooling Market and Trends. Rescue - Renewable Smart Cooling for Urban Europe 2014 https://ec.europa.eu/energy/intelligent/projects/sites/iee-

projects/files/projects/documents/d2.3_eu_cooling_market_0.pdf 